\title{
Canadian Manufacturers and Exporters Discovery Program
}

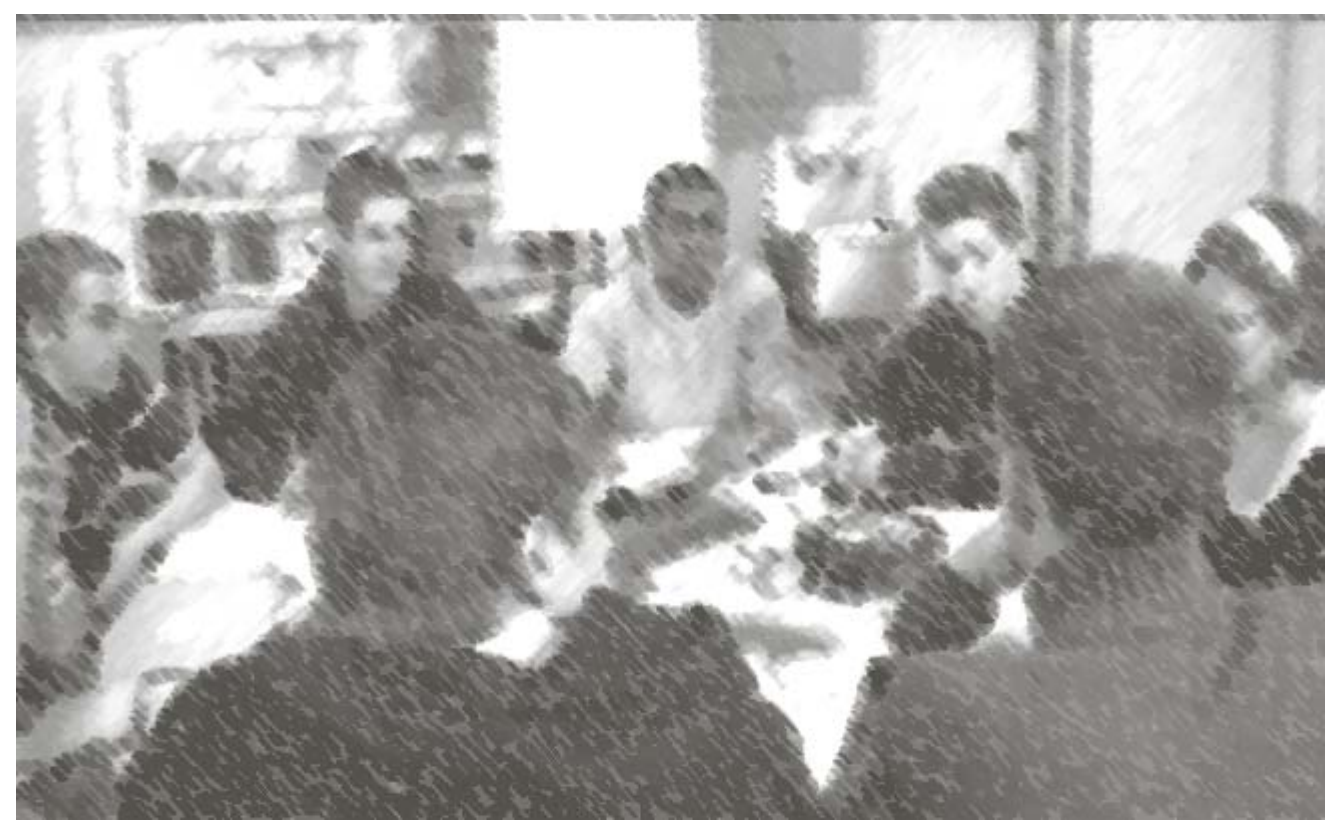

\author{
Christopher Laing \\ Instructor \\ Design Engineering \\ University of Manitoba \\ laingc@cc.umanitoba.ca
}

\begin{abstract}
In the news and ever present on the minds of people in the technology and manufacturing sector is Canada's need to replace nearly four hundred thousand skilled employees who will be progressively retiring over the next several years. To compound this problem, there has been a steady decline in student enrollment in the secondary and post secondary institutions in the science and technology areas (one of the main human resource feeds). Part of the reason for this can be directly related to a lack of awareness, not only to the diverse and exciting career opportunities found in contemporary manufacturing, but also just how important this sector of the economy will be to Canada's future. This paper explores the success of the CME (Canadian Manufacturers and Exporters) pilot
\end{abstract}

discovery program initiated by Design Engineering from the University of Manitoba. The initiative was directly aimed at secondary students from science, math, business, art, and technology programs. The main objective was to inspire these students by allowing them to experience first hand the many exciting facets of modern-day manufacturing. This was achieved by a hands-on approach to designing, building, and testing a project using their ingenuity to problem solve and the latest type of technology to fabricate their design. The success of this program was at the very least to be aware of a career option they may not of otherwise considered, and at the very most an opportunity to take the first steps to an exciting and rewarding career with the many possibilities that manufacturing has to offer. 


\section{Introduction}

Late summer 2006, John Graham, of IBM, who is a committee member of NSERC (National Science and Engineering Research Council) prairie regional office, brought together targeted groups that were either concerned and/or had a stake in finding a solution to replacing an aging workforce (manufacturing) consisting of 400,000 who will be progressively retiring over the next 15 years ${ }^{1}$. One of the major concerns that resonated from this meeting was the steady decline in student enrollment in the secondary and post secondary institutions in the science and technology areas (one of the main human resource feeds) ${ }^{2}$. There was much speculation circulated about the room to why this problem existed, however at this initial stage there wasn't an immediate solution, but rather a consensus that something could be done. The resolve and concern of everybody was evident by how focused they were on this issue, so much so, that even though we were at a baseball game, I doubt that anyone could have told you the final score. This is where the challenge started, there was a commitment and the knowledge that there was a solution; all it needed was a little time to research the phenomena and to develop an appropriate strategy.

\section{The basic principle}

Significant information came a week later that became an underlying principle of how we would approach this program. It was at a retirement party for Debbie Leiter, who was stepping down from her position as executive director of Skills Manitoba. During the congratulatory speeches, Rick Schroeder from Garden Valley Collegiate, who is also a Skills Manitoba board member, talked about the perception of some of his academic co-op students that volunteered at the last Skills 2006 provincial competition ${ }^{3}$. The vast majority of them had never seen anything remotely like this type of venue. They found the whole experience exciting especially seeing the effort and enthusiasm shown by the participants. More than one of these students commented to Rick that they never knew much about the skill trades; typically they were steered away from this area; they were told "don't waste your time with this you are going to university". Now more than ever, the notion that worthwhile jobs are only found with a university education is misguided; if it's the money, a secure future, and an interesting career where a high level of skill is required, then both options provide the answer ${ }^{4}$. Unfortunately this misinformed advice was perpetrated either by, teachers, counsellors, or family members. Regrettably, to add to this sad state of affairs and to confirm the indifference of some schools, one of the contestants that the coop student's were so impressed with, received little to no recognition from their school for winning the gold medal - not even an announcement over the PA; that is educationally reprehensible. This is a powerful illustration of how important it is to replace this lack of interest, not only with being informed about the available choices for these students, but even more so, is to encourage them to experience these options first hand, after all one of the fundamental reason for education is the preparation for tomorrow; lets hope as educators we all contribute to this noble cause. From the program's point of view it made it abundantly clear that there were a lot of students that could be possibly overlooked. To answer this we needed to reach out to a greater number of these individuals that have the same range of interests that match the diversity of many skills required with this opportunity. We also realized the significance of looking at the world through the student's eyes, understanding what is relevant to them, and provide them the opportunity to discover new challenges first hand. By adopting these principles we had the answer of how to approach this program.

\section{What's in it for them?}

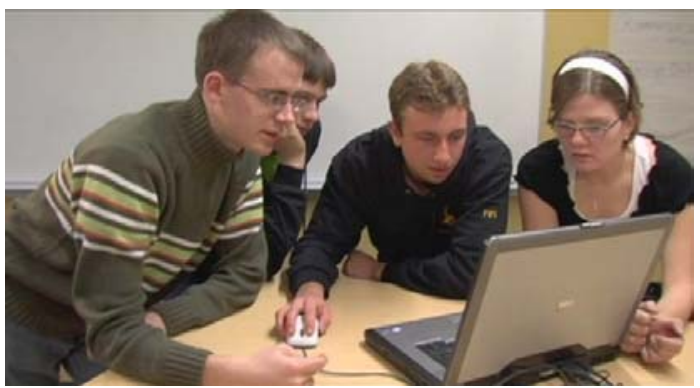

Figure 1 - Students making decisions

If we wanted to make a real impact on what these students were about to experience, we also needed to include the sort of influences that make them excited. Much of this can be related to personal interests, personal ability, family influence, money, and the status associated with success. When this is reinforced through the 
basic principles we've been talking about, then we have a powerful cocktail that has all the right ingredients to not only grab their attention but start them thinking about the possibilities. We have effectively opened the door - As far as the rest of the experience is concerned, we will guide and encourage them, but the outcome is up to them. We can take a lesson from the media they know how to make something exciting; there was a recent article that stated the TV series CSI (Crime Scene Investigator) has inspired $62 \%$ of young people between the ages of 16 - 24 to say they would consider getting into forensic medicine ${ }^{5}$. In this series, the environments and the hi-tech equipment they work with are definitely cool, but even more so, is the constant reinforcement of hip young professionals that can unravel the most complicated and seemingly unsolvable crimes provides an inspiration. Usually with a well written story you can become immersed with the identity of the protagonist; imagine a character that lives a lifestyle that reflects the ideal trends and someone who can be admired for their intellect and abilities. A TV show may be unrealistic in the time and the methods they use to solve these crimes, but the impact it is making - isn't. This is part of the picture we need to recognize and therefore provide students the opportunity to demonstrate their own capability to make use of their intellect, imagination and resourcefulness in a venue that reveals the cool, creative, exciting, and futuristic, side of science, engineering, and technology - imagine the impact we can make.

\section{The plan}

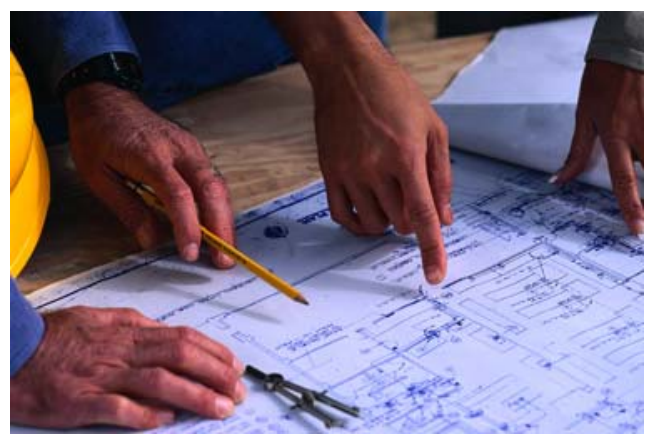

Armed with what we knew and using the above example it was easy to develop a plan. We recognized that the prevailing view of manufacturing and technology withholds the fact that it is one of the coolest and most interesting high tech careers to be in. Our job was simply to unveil this truth by letting the students experience it first hand; they were challenged in math, science, business, and art to develop their project, but in a very different way then you may expect: they were given unprecedented use of the same cutting edge technology industry leaders use. As an example, their design started with creating a 3D CAD model using the same software to design the Boeing 777, they also used Rapid Prototyping technology to produce a physical model, which started off as a digital concept on a computer and ended up as an object they could hold in their hands. Not only was the technology they were using real, but so was the challenge they were facing; much the same as in industry, the scope of this project required that teams were made up of students with dissimilar skills sets that needed to effectively work together and equally contribute to the success of the project. To be effective in delivering this program we needed to make sure that two basic principles were supported so that we could maximize a positive outcome and lay a solid foundation for the recurring projects. 1 . We need to make sure that this is student led, and 2. We stay the heck out of their way. The more work these student put into this project, the more validation they will receive for their effort. Our objective is to let the students know that they have the capability to be successful in this type of situation.

\section{1 The challenge}

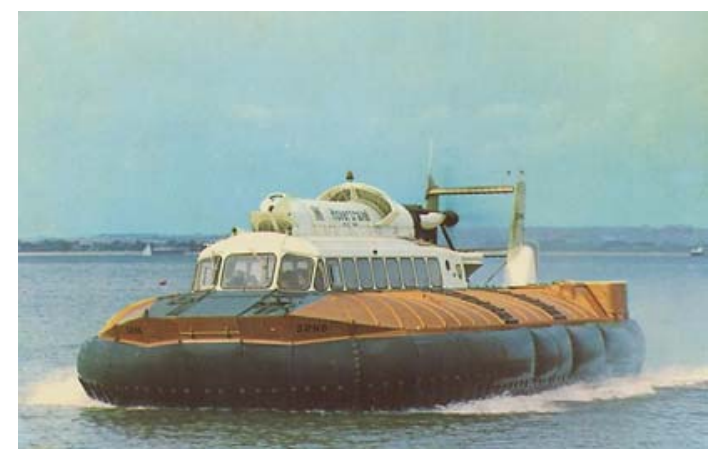

The challenge for this first CME Discovery Program was to design and build a radio controlled Hovercraft. It was required to lift off the ground and have controlled forward propulsion to maneuver over both water and rough terrain (obstacle course). There was certain constraints to ensure an even playing ground, as well as specific design criterion to guarantee that a definite level of achievement was met (leaving plenty of room for ingenuity). 
The following section, including the flow chart (Figure 2) describes the structure and some of the design considerations for the competition:

\subsection{Three phases}

The process was divided into the three phases designated as; the design phase, the preparation and training phase, and the final phase which is the presentation and competition. The following describes a brief overview of the program and tasks for each area:

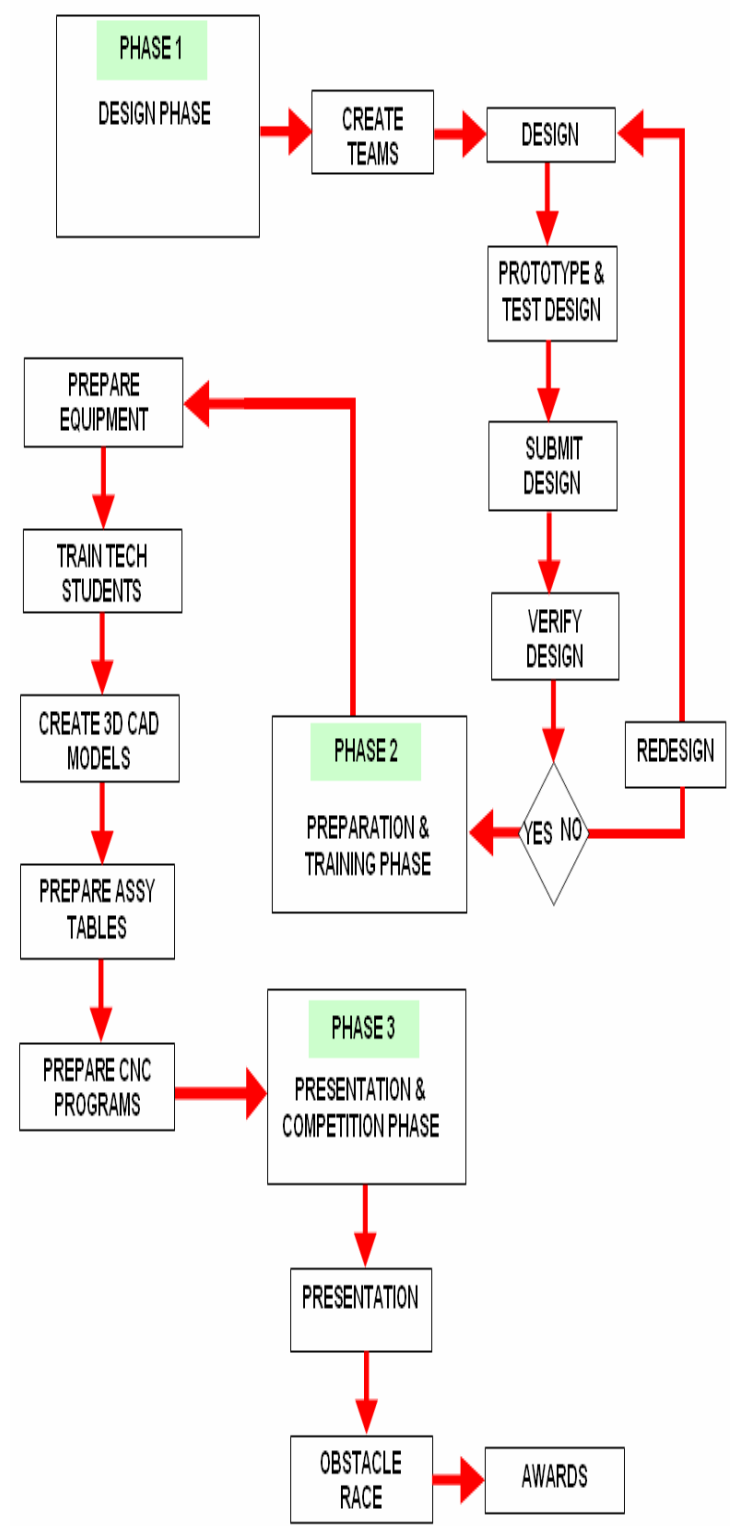

\section{Phase 1 - Design phase}

- Teams were made up of students based on interest and skill.

- An information package is supplied which includes the rules, design criterion, history, and background.

- A kit with all the components for designing and testing the project is provided.

- The design is worked out by students using math, science, art, and innovative thinking.

- Planning and costs are established by business students.

- Technology students help in the fabrication and testing of the prototype.

- Prototype is made, tested, and revised if necessary

- The final design is submitted

\section{Phase 2 - Preparation \& training}

- Design is verified to see if it needs to be resubmitted with changes, or whether it could proceed to final production.

- CAD models are produced from submitted design.

- Technology students are trained on hi-tech equipment in preparation for demonstrating at the summit.

- Prepare assembly tables to make the fabrication process faster

- Students fabricate their final projects at $\mathrm{U}$ of M CAD Technology lab.

\section{Phase 3 - Presentation \& competition}

- At CME Summit technology students run 5 stands with an interactive demonstration to 400 visiting high school students using high tech equipment.

- Technology students from Video Production film and interview contestants for live broadcast

- Students setup and test their project

- Design is presented to panel of judges (not pilot project)

- Race the obstacle course

- Presentation of awards

Figure 2 - Flow Chart 


\subsection{What was provided}

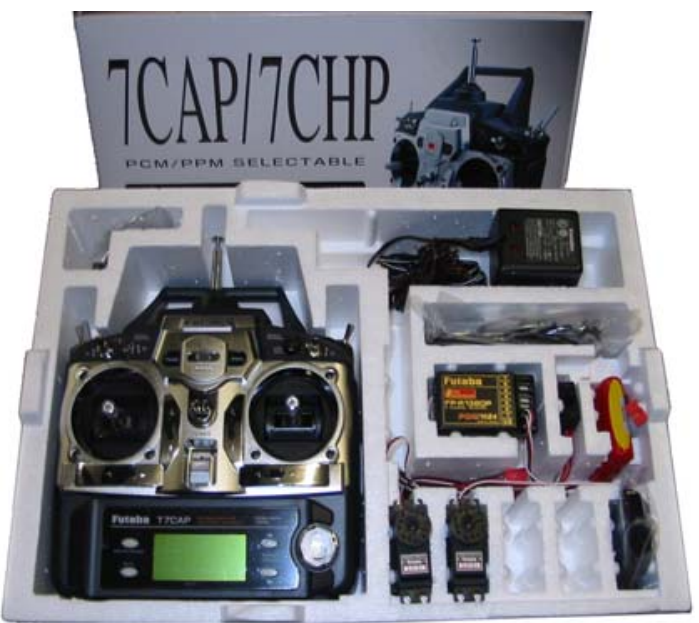

Figure 3 - Picture of RC components

We visited each of the participating schools where we introduced the project and gave them a kit that had all the components to build and design one radio control hovercraft. It consisted of one RC transmitter, a three channel receiver, two servos, four ducted fans (not all need be used in the design), three, batteries, switch, and antenna. The main body and secondary components, including the skirt, were to be designed on CAD and fabricated at a later stage. An information package was provided that described the history of the hovercraft, design criterion for the project, design considerations, as well as rules and responsibilities. Teachers were there strictly in an advisory role, which means they could provide background information and stimulate thinking, but in no way are they allowed to design the project - that privilege belonged to the students.

\subsection{Collaboration}

This program encourages teamwork and cooperation; in order to meet the entire design criterion students with dissimilar skills had to collaborate. As an example, math and science students are responsible for the integrity of such factors as balance, propulsions, art students have to make it look good enough to sell, and business students look after scheduling and costs. In order to make sure this happens; equal marks for all parts of the project are allotted at the end of the competition.

\subsection{The criterion}

The design each school comes up with is required for the engines to lift the craft, propel it forward, and carry a payload over an obstacle course which was made up with both land and water. A skirt will be vital in this role as it has to be able absorb the various obstructions presented by the terrain while still maintaining lift. Formulas are used to determine the force, size and, balance of the craft. Each team has to calculate the constants for weight and force of the supplied components. Basically what the students had to do is design a craft that not only worked with the fore mention constraints but also out performs their opponents.

\subsection{Promoting the design}

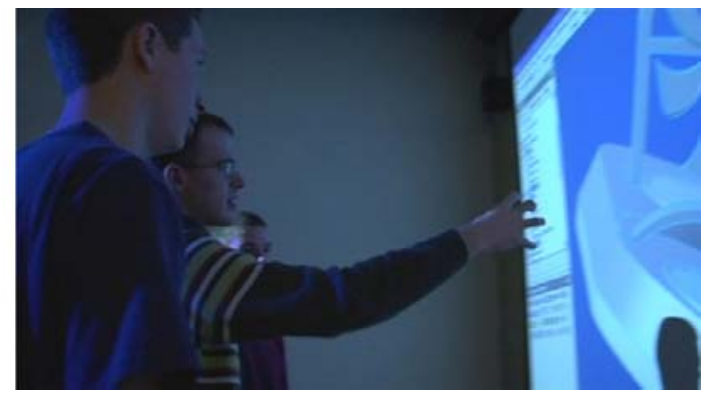

Figure 4 - Discussing the CAD design

In order to sell a product, it not only has to be functional but it also has to have commercial appeal. In this competition the way the design looks was very important, so students from the art department play an integral role as part of the design team. They need to take the form and function and make it marketable. If there is any inconsistency between these two elements a redesign may be been required as they had equal weight in the final marks. In future programs the contestants will also have to sell or describe their design in the form of a presentation made to a panel of judges. They will have to submit data showing the formulas, cost analysts, time management, design criterion and considerations, as well as, promotional material that will be in the form of posters and other media used to illustrate the concepts of their design. It should be noted that the marking for each area is equally weighted in the final tally to ensure inclusion of all skill sets for this contest. 


\subsection{Design Constraints}

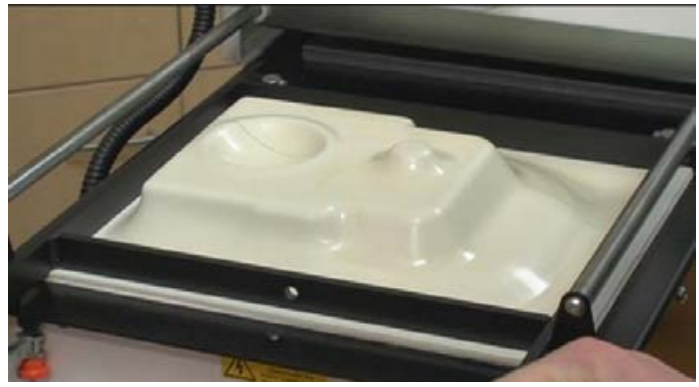

Figure 5 - Hovercraft shell in the vacuum forming machine

The material and size of the hovercraft was reflected by the constraints of technology they were using in the fabrication process. The design was made out of several components which include plastic, rubber and metal. It also required a circuit board and wiring harnesses for the power supply and servos. It could not exceed a width of 10 inches, a length of 14 inches, and a height of 3 inches (every vertical inch requires one hour of build time on the rapid prototyping machine)

\subsection{Resources}

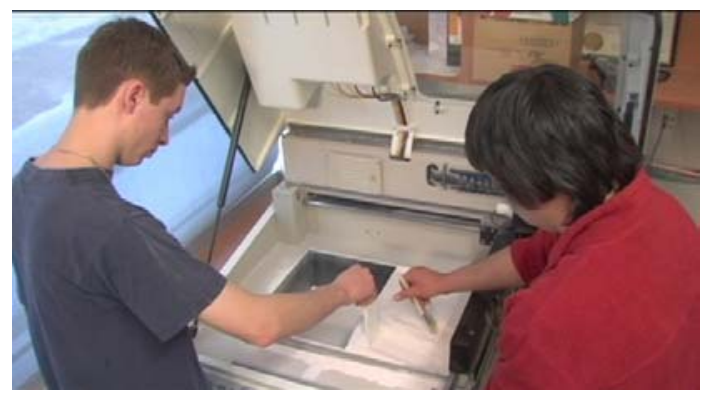

Figure 6 - Student working on Rapid prototyping machine

The technology being used to fabricate the components required 3D CAD models. This was to be created by high school students as part of the technology support (students only). The software used to create the 3D models will be CATIA (Computer Aided Three dimensional Interactive Application). The digital models created by this software will be exported as STL (stereo lithography) files for the Rapid prototyping machine. This in turn will produce the physical models used as masters for the vacuum forming process (forms a plastic shell of the body of their craft). In addition the 3D models can be rendered to produce art work for the posters submitted to the judges (artwork wasn't required for this initial pilot program).

\subsection{At the event}

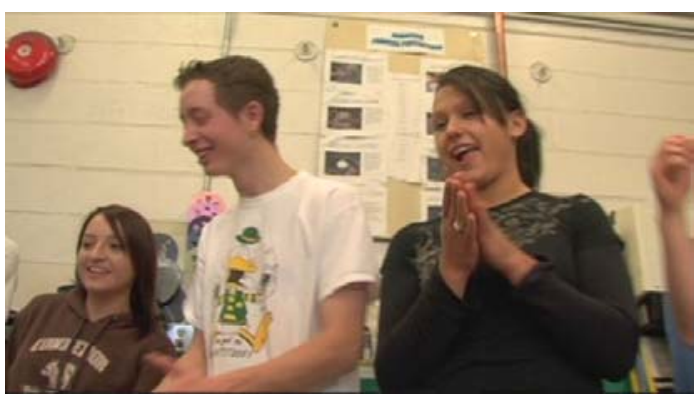

Figure 7 - Students cheering

400 students from various high schools were bussed to the CME summit which was held at the Winnipeg Convention Centre. They not only saw the radio control hovercrafts being put through its paces, but they had the opportunity to participate in an interactive program where they were shown the various processes and hi tech equipment, demonstrated by the students and teachers from the participating schools. They went through a total of five stations until they gathered up all they needed to build their own working version of a mini hovercraft that they could take home. The first station represented the design phase where Crocus Plain students demonstrated how they used CAD to design the hovercraft model. The second station was a rapid prototyping centre where the CAD files were turned into physical models that in turn would be used in the next process. The third station was the vacuum forming machine where plastic sheets are heated and formed over the rapid prototype masters. The fourth station was the fabrication area where students cutout and assembled their own hovercraft model (Presoldered electronics, props and decals were supplied). The fifth and final station was an area to test-drive their new hovercrafts. This interactive portion of the program was so successful that not only did the students enjoy making these hovercrafts, but people from industry started making them (who weren't supposed to). I even heard a rumor that one of these mini hovercrafts ended up on the minister of education's desk. (Just to let you know each mini hovercraft cost under $\$ 5.00$ dollars to produce). 

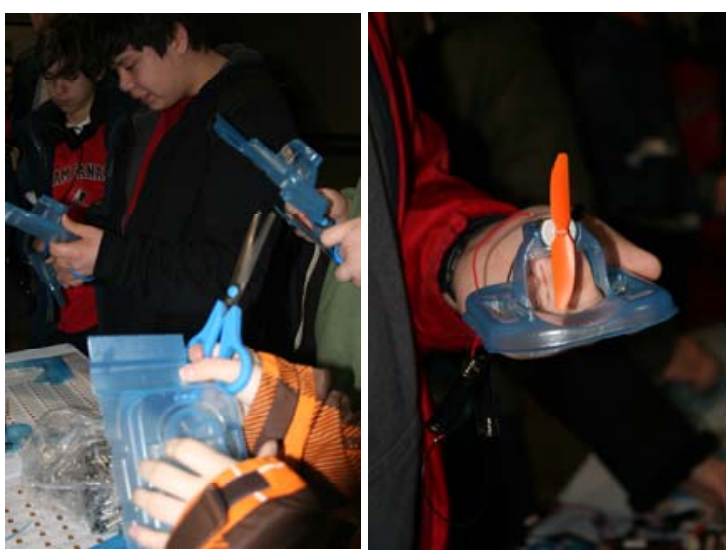

Figure 8 - Mini hovercrafts being constructed picture by: Alexandra Argueta, Tec Voc Student

After this they were able to visit industry booths and then see the radio controlled hovercrafts in action - competing in an obstacle course which consists of ramps, pylons, and water hazards.

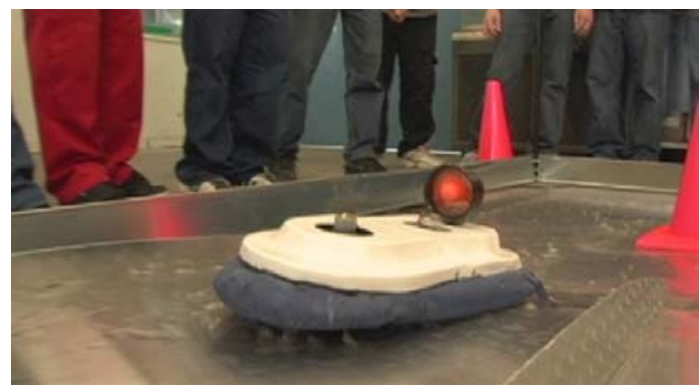

Figure 9 - RC hovercraft being put through its paces

The next time this program is run competing teams will be live on the air being broadcast at breakfast, lunch and dinner for this event. They will be interviewed by students from the video production program at Tec Voc. It will be much the same content as reality TV programs like Iron Chef. At the end of the day the video team will put together a recap of the event just prior to the presentation of awards.

This event will be a chance for industry to see the talent and capacity of our youth that at the very least will provide assurance that the future is in good hands. When we give these students the opportunity - they will not only meet the challenge but they will excel. This initial project is the right thing to do, which is the key component to making something good - work. It is not only rewarding for everyone involved, but even more so, it will motivate industry to get involved and support this effort which is significant in its growth.

\section{Conclusions and Recommendations}

The pilot program was quite an undertaking with many hurdles to cross (mainly man made). Notwithstanding the first attempt with this project made quite an impact with the students, the participating schools, the people from industry, and the government. It offered the students a taste of the same dynamics they would face in the real world including the difficulties and as well as the rewards. What is really pleasing in this entire program is not only seeing these students overcome these obstacles, but also knowing they had it in them to prevail over the challenges they faced. I had one person tell me that this was too difficult for them and they wouldn't be able to complete the design in the time we gave them. To reinforce this point, I was shown a curriculum guide with an example of one task that would take two weeks to learn. I replied "don't worry these students will surprise you" - and of course they did. I suppose you could say this is an example of the difference of training vs. education. Students are able to achieve incredible things when they are motivated and given the opportunity discover what they are capable of.

This discovery program has the potential to reach out to many more students then ever before. It will allow them to experience the cool and creative side to engineering and technology. It unlocks the possibilities and opens the door to a new and exciting future.

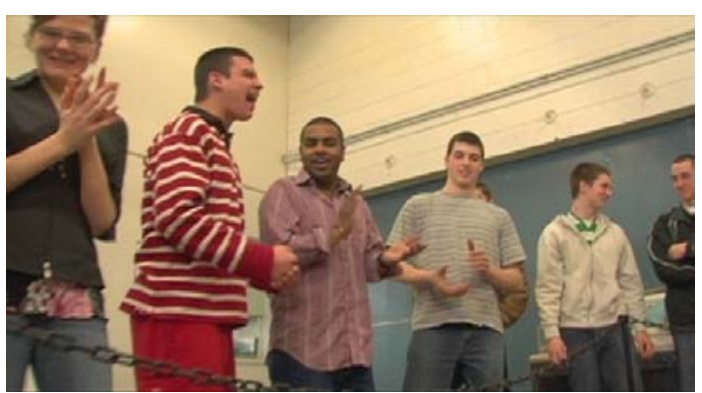

Figure 10 - Students cheering 


\section{Appendix A}

7 Student reports written by co-op students, provided by Garden Valley Collegiate:

(Names withheld by request)

\section{Response to Skills Manitoba}

Written by: Student \#1

April 26, 2006

On Wednesday April 12, 2006 at 12:30 p.m., our Cooperative Education class left for Winnipeg. When we got to Winnipeg, we stopped for something to eat and then went to the Red River College Campus on Notre Dame. We were there to help with Skills Manitoba.

When we first got to the campus, nobody really knew what they wanted us to do. After a while, they gave us signs to hang up. We walked around the entire campus hanging up signs and figuring out where everything was. We got lost a few times and also got frustrated a few times but overall it went pretty good. When we were done hanging up signs, we went to the automotive section and took apart the cars. That was the best part of the day because I learned a lot of new things and it was very interesting. When we were done there, we went back to our hotel and went swimming for a while. Then we went for a very late supper and then went back to the hotel and just hung out for a long time.

The next morning we were up bright and early. We got ready and went back to the campus. Our first job was to register all 500 competitors. That was a fun job. After that was all done, some of us had to deliver safety binders to all the areas. This was frustrating because we kept getting lost and having to go back to the same spot over and over again. After that job was done, we had to deliver lunches to everyone. Again we had to walk around the entire campus with big 
boxes of lunches and drinks. Then we got to eat our lunches and just relax for a

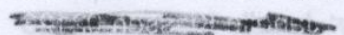
while. We then went to the gym and watched the award ceremonies. Once that was over we had to go around the campus again taking down all the signs. When that was finished we piled into the van, stopped for some supper and then headed back home to Winkler.

These two days were a lot of fun. They were tiring, frustrating at times, but overall it was a really good time. I'm glad that we went and helped out because it was a good experience. It was cool to see what all goes on at a competition like that. I'm used to going to skating competitions, but this was totally different. I had never really heard of this competition before which isn't good because its good experience for students. Teachers should give their students more information about it so that they know what's all involved. I think that this is an experience that more students should get to have.

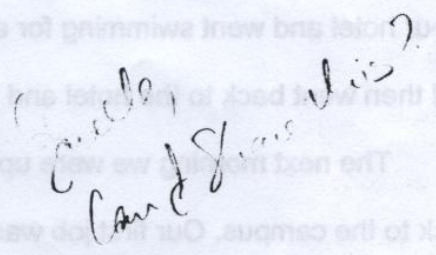




\section{Skills Canada \\ Student \#2}

When we went to help out at Skills Canada in Winnipeg on March 12 and 13, I learned a lot of things. I think that it was a really good experience and it opened my eyes to a very important event. While I was there I noticed that the idea of working in a trade area was stressed. You often don't see this anymore because most people encourage you to go to university and do something "more important". The people working in the offices and around the building seemed to be very excited for the event and this helped to promote work in trade areas.

The students that were competing seems to enjoy their trades and excelled quite well in them. It was really good to see so many Manitobans that still want to get evolved in skilled trades. People often look past their accomplishments and don't appreciate the work what they do. I noticed that even though some people from our school won events they weren't really recognized by our school. All they got was their name in the communicator and that was it. I think that we could have at least mentioned their names at an assembly or something, after all some of them did win sliver and bronze in their categories. This shows that people are less interested in skilled trades and don't realize the importance that they have in our society.

Going to Skills Canada really helped to show me to what kind of trades there are and how many different areas you can go into. I would definitely consider going to help at an event like this again. I think people should take the time to go to an event such as this and learn about trades in Manitoba. Maybe next time they would think before they discourage work in these areas. 


\section{Skills Canada Manitoba}

We had the chance to volunteer at the Skills Canada Manitoba competition in April and had a really good time. I got there at 6:30 and was taught how to help with the registration early. By the time my group arrived at 7:30 we were pretty busy helping direct people to the right tables and giving them the registration bags. It was a lot of fun manx.

and we got to meet a lot of the competitors.

Anna gave Trudy and I a tour of the Red River College and then we packed lunches and helped deliver them. It was tough finding the right rooms and different buildings; but we got all of them there on time. We had some time to-also eat lunch and did so. After lunch Anna and I went to check out some of the skills being performed. I was a little disappointed with the floristry because I had seen better at Heide's here in Winkler and the hairstyles were not that interesting either. We watched a bit of the robotics competition and that's when I realized how important this was to the people competing. They were trying really hard and were working really well as a team and I was glad to see that the group of girls won that competition.

We also got to try out one of the skills, masonry. We walked into the room and the walls were lined beautifully with bricks and curves and it looked really good. A bunch of the guys competing there asked us if we would like to lay a brick into the wall. We tried it and found out that it was really hard, even the mortar was heavy. But they were so helpful and encouraging and let us sign our names on our bricks. I also learned that there were no women in this trade in Manitoba, but that the pay is really good. I figured I could do this kind of work but the teacher there said that there is a lot of hard work before I would earn such good wages. 
After the competitions had finished we helped set up for the awards ceremony. Anna and I sat with the photographer helping with numbers and competition names. It was a lot of fun and good to see that there were a few competitors from our school who had won.

I think that overall this was a really good experience and I had a lot of fun helping out. It was also a great way to discover what kinds of trades are out there and that people are needed to do them. I thought it was also cool that we got time to go watch the competitions and try a few out.

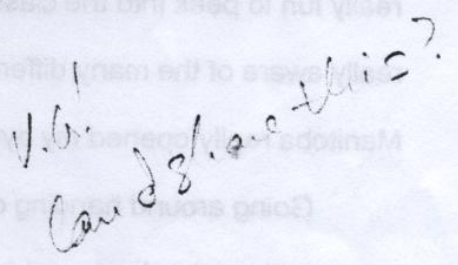




\section{Student \#4}

Skills Canada

According to me the skills Canada competition was a real good success. Not only was it a good experience, it was also fun. With skills Canada all the students have a reason for showing off their talents and skills. Often this encourages people to become better and learn more for what they want to do. Plus if you win a medal you feel good about being one of the top students in the province.

The reason skill Canada is so effective' because ther/ students have something to work for. They might study extra hard just to do well in the competition. You tend to work and learn better when you are in a competition environment. This might be in the classroom, the workplace, or even in the Skills Canada competition. They also get to meet other students from the same branch of trade and might make good connections which will be important later on in their life.

From the volunteering side of the competition, I thought it was pretty fun. You get to know someone better when you work with them. I thought it would be pretty boring since I didn't really know anyone of the class. We did get along pretty well and that's what made it double the fun. When you are volunteering you don't work on a tight schedule as if you were at work. You usually stay well over your 8 hours and you leave when the job is done. I wouldn't call that work that we did and it was pretty fun to do something different every couple of hours. We also did get more freedom in that we got to manage our own "jobs" in that who did what and where.

Skills Canada was the first time I had done something like this and it was a real good experience. You respect other people more for the effort they put in when they 
don't get anything out of it that they can count in bank account. You still get a lot out of something like that, though. 


\section{Student \#5}

\section{Skills Canada Manitoba}

Skills Canada was a really good experience and I really enjoyed our trip. It was a lot of work and kept us on our toes almost the whole day long but being able to help out was really fun.

It was really amazing to see how many students from Manitoba were willing to compete at the competitions. There were a lot of different careers and events and it was really fun to peek into the classes and to see what was going on in them. I was never really aware of the many different kinds of careers you can get into and skills Canada Manitoba really opened my eyes to that.

Going around handing out lunches was probably the hardest part of the day because the school was so big and then events were all over the place. The lunches also got really heavy and we kept taking the wrong elevators and kept getting lost as a result. Registration was probably the easiest job and you got to meet the people through that which made it really interesting.

I really enjoyed watching the award ceremony even though it did get kind of boring at the end because there were so many awards, it was especially cool to see people from our school winning a gold metal.

Getting to meet Barbara Bowes who writes the articles that we have to do reports about was cool to see as well. Because you could now put a real face behind the articles instead of just seeing the little picture in the corner of the articles, seeing her made it more real. 
I really enjoyed "wrecking" cars as well. It would have been really hard to locate some of the little parts that we took of them for the students and I was really impressed when a guy from our school got $2^{\text {nd }}$ or $3^{\text {rd }}$ place.

I really liked hanging out at the hotel as well. We had a lot of fun and got to know each other better because of that.

I enjoyed going on this little trip because I walked away with more knowledge than before and I recommend it for other classes as well. Thank you for giving us this opportunity to volunteer. 


\section{Skills Canada Manitoba Competition \\ Student \#6}

On April 12 and 13 I had the privilege of volunteering at the Skills Canada competition in Winnipeg at Red River College. I had never heard of Skills

Canada until we started co-op ed. I though I would be really board because I am not into the trades very much but I found the experience thoroughly enjoyable.

To start with, a good part about the whole experience was the people I was with they made everything so much fun. It is great learning how to work and get along with different personalities and ways of doing things. I am finding more and more when I work with people if I can humble myself and work as a group and accept everyone's ideas and compromise things are done better and it is more enjoyable to execute plans.

One thing that surprised me about the skills competition was how few Wree volunteers there was and how much work our small group from Winkler had the opportunity to do. I found myself sweating from carrying things and running all over the place. I expected a number of volunteers from around Winnipeg mostly 1, , :

because it was a provincial thing, but there wasn't. When I first saw that we were the main volunteers I thought it was unfair that we would have to do so much work but, it felt good to help make the whole thing a huge success. I love the $\left.t_{1}^{1 / 2}\right)_{1}^{1}$ feeling of being a part of something successful and bigger than myself. The more experience I get with being involved with large events and even at workplaces, I find that if I can think of it as my own or how I would feel if I was in charge what kind of volunteers or employees I would appreciate. 
Skills Canada is something that everyone should know about. I wish I had known about it sooner. I always thought that trades were dead end or boring jobs but when I see events like skills it makes me want to be a part of it. I find that the way something is presented or advertised greatly affects whether or not it is successful. I would like to help advertise skills and make it an even bigger success than it was this year.

This whole trip was awesome, something I would definitely do again if I had the chance. I got to make connections with people that have huge connection to jobs. Hopefully I can use what l've gained through skills as a gateway into my career whatever it may be.

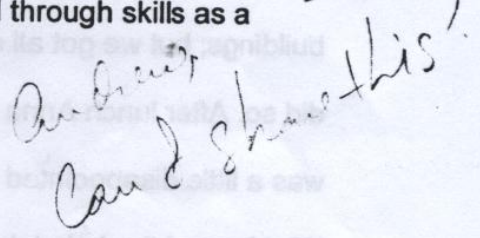




\section{My Skills Canada Experience}

Going to Skills Canada for me was interesting and fun, but at the same time I learned a lot. It was a great experience in which I learned about the several trades, and got a different perspective of the trades. A key point that really opened my eyes was seeing how several of the students had their individuality and liked being unique. In Winkler you see a lot of the same because no one wants to be different. At Skills Canada they weren't afraid to be themselves, but : te. 0 , rather wanted to be different.

I also saw a lot of effort being put into the work, and no one was put down, instead they were encouraged. I liked how the students were so excited when they won, but then turned around and cheered for others as well. There was so much teamwork in some of the groups that even when they didn't win, they were still celebrating. Even though not every one got a medal, they were still acknowledged for their attemp? Although, the ones who did score the highest either got a gold, silver, or bronze medal as well'some sort of gift of thanks.

Another element about Skills Canada that really caught my eye was when they were willing to demonstrate certain trades. I experienced this when Heather and I were observing the different rooms and trades. When we walked into the Masonry shop the guys working were quick to ask if we wanted to try being a mason. They wouldn't take no for an answer, and took their time trying to teach us how to build a wall. I think this shows how committed and willing these people are. Even when I dropped the filling mixture on the ground, it wasn't a frustration 
to them, just another area they could help out in. When people take their time to try and teach others their trade it really makes you think twice about considering that trade.

When I saw how many students were taking part and giving it their all, I think that gave me hope of a future. I was more encouraged to find a trade that would fit my talents and abilities. I think being a volunteer at Skills Canada made me feel special because we weren't getting anything from it, we were just helping out. Everyone was so grateful when we gave them their lunches, it made you feel like you were really making a difference.

The people at the school were considerate and when we got lost they willingly helped us find certain rooms. At one point on the second day, when we were carrying lunches we had to get onto the elevator, and the guys in the elevator actually offered to carry the lunches for us. Everyone was just so considerate; it felt like we were more like guests than volunteer workers.

When I first thought about Skills Canada I was excited to help out and experience something new, but I never expected to learn this much. I think that if I could go again, I would in a heartbeat. I really enjoyed working and even watching the students participating was interesting. I think that every Cooperative ? education class should get the chance to participate in Skills Canada, because the experience will be so good for them, and they'll find it exciting and uplifting. Overall this was one of the best educational school trips that I have ever been on. I give it a ten out of ten, and if I were to change anything about the experience it would be switching vehicles so that I could work more. 
References:

${ }^{1}$ Canadian Manufacturing and Exporters [hon. Perrin Beatty], Ensuring the Future of Canadian Manufacturing, Feb 2005.

${ }^{2}$ Government of Canada [Ruth Fawcett, Science and Technology Division], Science Education in Canada, Aug 1991.

${ }^{3}$ Appendix A, Student reports written by co-op students, provided by Garden Valley Collegiate, names withheld by request, May 2006.

${ }^{4}$ Educators guide, Myths and Realities of Skilled Trades Careers

[http://www.careersintrades.ca/all/EducatorsGui de-English.pdf], Sec. 2:4 Pg. 9 of 60, June, 2007

${ }^{5}$ Thinking outside the box, The Guardian jobs, Career advice,

[http://jobsadvice.guardian.co.uk/graduate/story/

0,,1789345,00.html], June, 2006 